\title{
A retrospective study on disease management in children and adolescents with phenylketonuria during the Covid-19 pandemic lockdown in Austria
}

\author{
Marion Herle', Michaela Brunner-Krainz², Daniela Karall³, Bernadette Goeschl', Dorothea Möslinger' \\ Joachim Zobel ${ }^{2}$, Barbara Plecko², Sabine Scholl-Bürgi ${ }^{3}$, Johannes Spenger ${ }^{4}$, Saskia B. Wortmann ${ }^{4,5}$ and \\ Martina Huemer ${ }^{6,7^{*}}$ (D)
}

\begin{abstract}
Background: In classical phenylketonuria (PKU) phenylalanine (Phe) accumulates due to functional impairment of the enzyme phenylalanine hydroxylase caused by pathogenic variants in the PAH gene. PKU treatment prevents severe cognitive impairment. Blood Phe concentration is the main biochemical monitoring parameter. Between appointments and venous blood sampling, Austrian PKU patients send dried blood spots (DBS) for Phe measurements to their centre. Coronavirus disease-19 (COVID-19), caused by the SARS CoV-2 virus, was classified as a pandemic by the World Health Organization in March 2020. In Austria, two nationwide lockdowns were installed during the first and second pandemic wave with variable regional and national restrictions in between. This retrospective questionnaire study compared the frequency of Phe measurements and Phe concentrations during lockdown with the respective period of the previous year in children and adolescents with PKU and explored potential influencing factors.
\end{abstract}

Results: 77 patients (30 female, 47 male; mean age 12.4 [8-19] years in 2020) from five centres were included. The decline of venous samples taken on appointments in 2020 did not reach significance but the number of patients with none or only one DBS tripled from $4(5.2 \%)$ in 2019 to $12(15.6 \%)$ in 2020. Significantly more patients had a decline than a rise in the number of DBS sent in between 2019 and $2020\left(p<0.001\right.$; $\left.\mathrm{Chi}^{2}=14.79\right)$. Especially patients $\geq 16$ years sent significantly less DBS in 2020 ( $T=156, p=0.02, r=0.49$ ). In patients who adhered to DBS measurements, Phe concentrations remained stable. Male or female sex and dietary only versus dietary plus sapropterin treatment did not influence frequency of measurements and median Phe.

Conclusion: During the COVID pandemic, the number of PKU patients who stopped sending DBS to their metabolic centre increased significantly, especially among those older than 16 years. Those who kept up sending DBS maintained stable Phe concentrations. Our follow-up system, which is based on DBS sent in by patients to trigger communication with the metabolic team served adherent patients well. It failed, however, to actively retrieve patients who stopped or reduced Phe measurements.

\footnotetext{
*Correspondence: martina.huemer@lkhb.at

${ }^{6}$ Division of Metabolism and Children's Research Center, University Children's Hospital Zürich, Zürich, Switzerland

Full list of author information is available at the end of the article
}

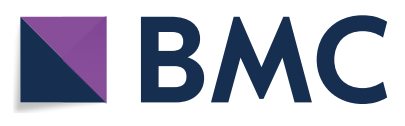

(c) The Author(s) 2021. Open Access This article is licensed under a Creative Commons Attribution 4.0 International License, which permits use, sharing, adaptation, distribution and reproduction in any medium or format, as long as you give appropriate credit to the original author(s) and the source, provide a link to the Creative Commons licence, and indicate if changes were made. The images or other third party material in this article are included in the article's Creative Commons licence, unless indicated otherwise in a credit line to the material. If material is not included in the article's Creative Commons licence and your intended use is not permitted by statutory regulation or exceeds the permitted use, you will need to obtain permission directly from the copyright holder. To view a copy of this licence, visit http://creativecommons.org/licenses/by/4.0/. The Creative Commons Public Domain Dedication waiver (http://creativeco mmons.org/publicdomain/zero/1.0/) applies to the data made available in this article, unless otherwise stated in a credit line to the data. 
Keywords: Health system resources, Patient self-management, Adherence

\section{Background}

Phenylketonuria (PKU) is an inborn error of phenylalanine (Phe) metabolism in which the enzyme phenylalanine hydroxylase that metabolises Phe to tyrosine is functionally impaired due to variants in the $P A H$ gene $[1$, 2]. Inheritance is autosomal recessive. PKU is a rare disease with an incidence of about 1:10.000 [1,2]. Untreated, classical PKU leads to severe, early cognitive impairment caused by Phe neurotoxicity. PKU is an ideal disease for newborn screening as cognitive decline is prevented by treatment. Phe concentration is the main biochemical monitoring parameter [1-3].

Mainstay of treatment is a natural protein-restricted diet mostly complemented with special Phe-free amino acid supplements. The oral drug sapropterin can lower Phe in patients with tetrahydrobiopterin (BH4) responsive variants. The recently introduced subcutaneously applied enzyme replacement therapy for PKU, pegvaliase, is licensed for patients from 16 years [3].

In Austria, most patients with PKU are followed in five metabolic centres. Patients come for appointments including venous blood sampling for a complete profile of amino acids and other parameters one to four times per year, depending on age and metabolic stability. Between scheduled visits, patients send dried blood spots (DBS) for Phe (and tyrosine) measurements to the centre. If Phe exceeds the recommended range, the metabolic team actively contacts parents and patients by phone for counselling.

Coronavirus disease-19 (COVID-19), caused by the SARS CoV-2 virus, was classified as a pandemic by the World Health Organization in March 2020. The first Austrian cases of SARS CoV-2 virus infections became evident on February 25th 2020 and the first deaths from COVID-19 occurred in March 2020. A nationwide lockdown including school closures was installed from March 16th to the 4th of May 2020, followed by partial re-opening until the summer holidays in July and August. During the second wave of the pandemic, strict regulations from September 2020 were followed by a second lockdown phase with school closures from November 17th to December 7th 2020 [4].

Although children and adolescents are at less risk for severe courses of COVID-19 disease, they may suffer from indirect effects of the pandemic such as impaired access to chronic and acute care, obesogenic and generally more unhealthy eating and behavioural habits associated with the altered everyday life due to pandemic-associated restrictions and regulations as well as psychological burdens [4-6]. The indirect impact of the pandemic proved even worse for children with chronic health conditions [6]. Globally, inborn metabolic disease-related services were reduced to $60-80 \%$ of normal during 3 months of lockdown in 2020 compared to the same period in 2019 indicating a profound impact of the restrictions on patient management and care [7]. For PKU, it is unknown whether impaired management and care applies to all affected children, or mainly to socially deprived individuals [8] or to those with pre-existing psychological burdens [9].

This retrospective study aimed to investigate whether the number of Phe measurements and Phe concentrations differed between times of lockdown compared to the same period of the previous year 2019 and whether age, sex, metabolic control and type of treatment influence changes in number of measurements and Phe concentrations.

\section{Methods}

This retrospective survey was restricted to children with classical PKU who were in 2019 already attending school and who would thus be most affected in their everyday life by the lockdown measures. Metabolic teams of five metabolic centres in Austria in which approximately $90 \%$ of the country's paediatric PKU patients are followed answered survey questions on sex, year of birth and treatment (diet, sapropterin, and enzyme replacement), number of Phe measurements, Phe concentrations from DBS sent from home, number of regular metabolic clinic visits and Phe concentrations from venous samples taken on these occasions, and the number of telemedicine consultations in their patients with classical PKU. Reporting periods for Phe measurements were from 16/3/2020 to 4/12/2020 and from 16/3/2019 to 4/12/2019 (comparison period). Measurement intervals were interpreted according to the age-adjusted control frequency for Phe and Phe target concentrations as recommended by the centres.

\section{Statistical analysis}

Age, sex, type of treatment, number of Phe-measurements, number of regular metabolic clinic visits, number of telemedicine consultations and average Phe concentrations (from DBS and venous samples) for the two measurement periods were analysed descriptively. If patients had more than one Phe measurement from venous samples, the mean was calculated; for Phe measured from DBS, the median (Mdn) was used. The number of patients with a median Phe concentration (from DBS) 
within the recommended range during one or both measurement periods was determined and confidence intervals ( $95 \%$ CI by modified Wald method) were computed.

Since average Phe concentrations and number of Phemeasurements were not normally distributed between patients, Wilcoxon signed-rank test was applied to compare these variables between the two measurement periods. Analyses were repeated for subgroups of patients (age groups: $8-10 / 10-12 / 12-16 />16$ years; sex: male/ female; treatment: with/without sapropterin, average Phe from DBS in 2019: within/above recommended range). For significant results, effect sizes (r) are reported. By convention, effect sizes $>0.2$ are considered small effects, $>0.5$ medium effects and $>0.8$ large effects [10].

For categorical data (0 vs. $1-2$ venous samples; average Phe from DBS within versus above the recommended range) Fisher's exact test was calculated. Calculations were done with SPSS (IBM SPSS Statistics 25.0) and Graphpad [11]. P values (two-tailed) $\leq 0.05$ were considered statistically significant, for multiple comparisons, Bonferroni-Holm-correction was applied.

\section{Results}

Data from 77 school-age children and adolescents (30 female, 47 male; mean age 12.4 (8-19) years) followed in five metabolic centres in Austria were included. Twenty (26\%) were between 8 and 10 years, $18(23.4 \%)$ between 10 and 12 years, 19 (24.7\%) between 12 and 16 and 20 (26\%) were between 16 and 19 years old. All were on dietary treatment and 11 (14.3\%) were additionally treated with sapropterin.
Most centres recommended monthly Phe-measurements for children between 6 and 16 years, but some centres extended intervals in very stable patients. Recommendations to patients older than 16 years were less homogeneous with intervals from monthly to every 6 months. Interestingly, recommendations for Phe target concentrations differed between centres. All except two recommendations followed at least one of the available guidelines or recommendations [12-16]; 13 of 20 recommendations followed the European guidelines [14].

The average number of Phe measurements from DBS $(\mathrm{Mdn}=7$ in 2019 and 6 in 2020) differed significantly between the two measurement periods $(T=1602$, $p<0.001, r=0.28)$. Overall, the number of patients with none or only one DBS increased from 4 (5.2\%) in 2019 to $12(15.6 \%)$ in 2020 . Ten patients had not sent a single DBS to the laboratory in 2020. Significantly more patients had a decline than a rise in their number of DBS sent in for Phe measurements from 2019 to $2020(p<0.001$; $\left.\mathrm{Chi}^{2}=14.79\right)$ (Fig. 1).

Subgroup analysis according to age groups revealed that patients $\geq 16$ years sent significantly less DBS in $2020(T=156, p=0.02, r=0.49)$.

Measurements from venous blood samples are exclusively taken at appointments to the outpatients' clinic. Whereas 13 patients (16.9\%) had two appointments in 2019 , only one patient (1.3\%) had two regular checkups in 2020 (Fig. 2). Appointments to the outpatients' clinic were not generally replaced by telemedicine consultations; only four patients $(5.2 \%)$ received such a consultation. The number of patients without any

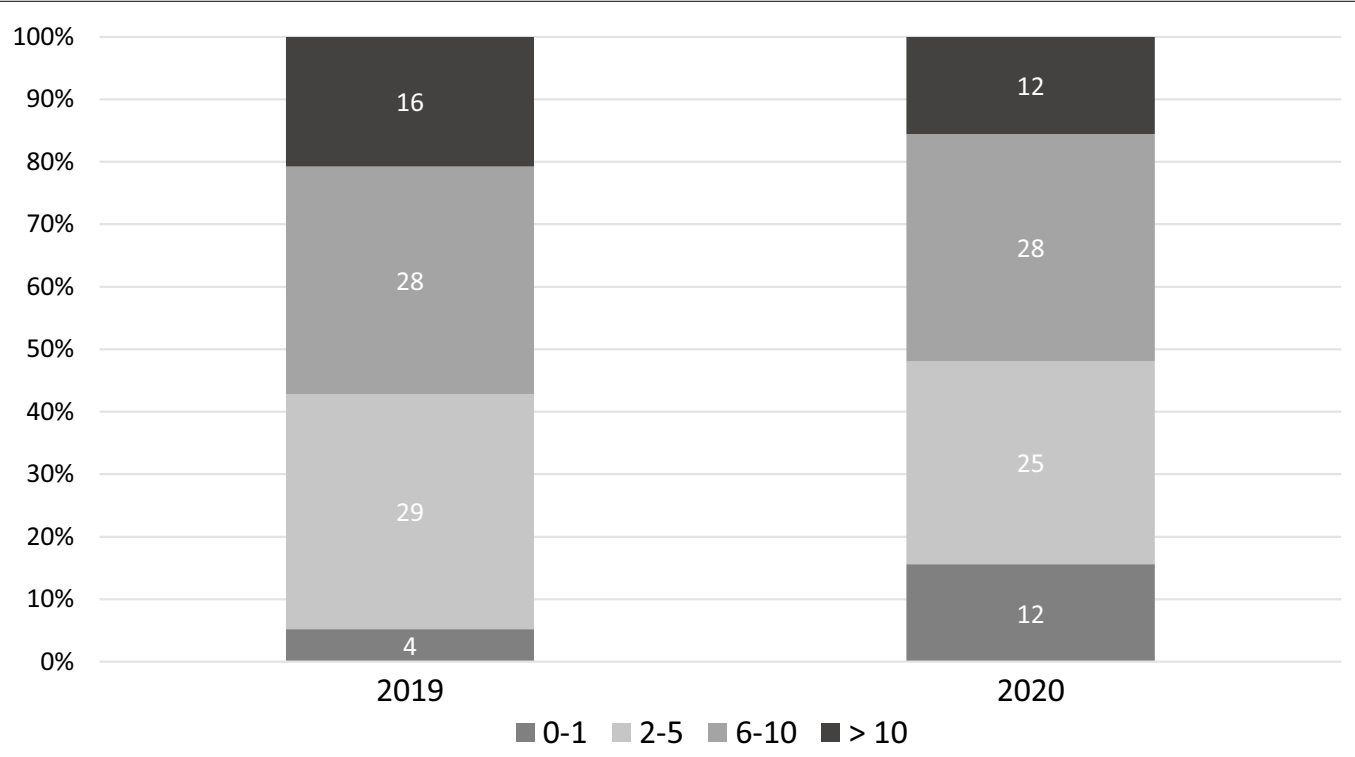

Fig. 1 Phe measurements from DBS in 2019 and 2020 


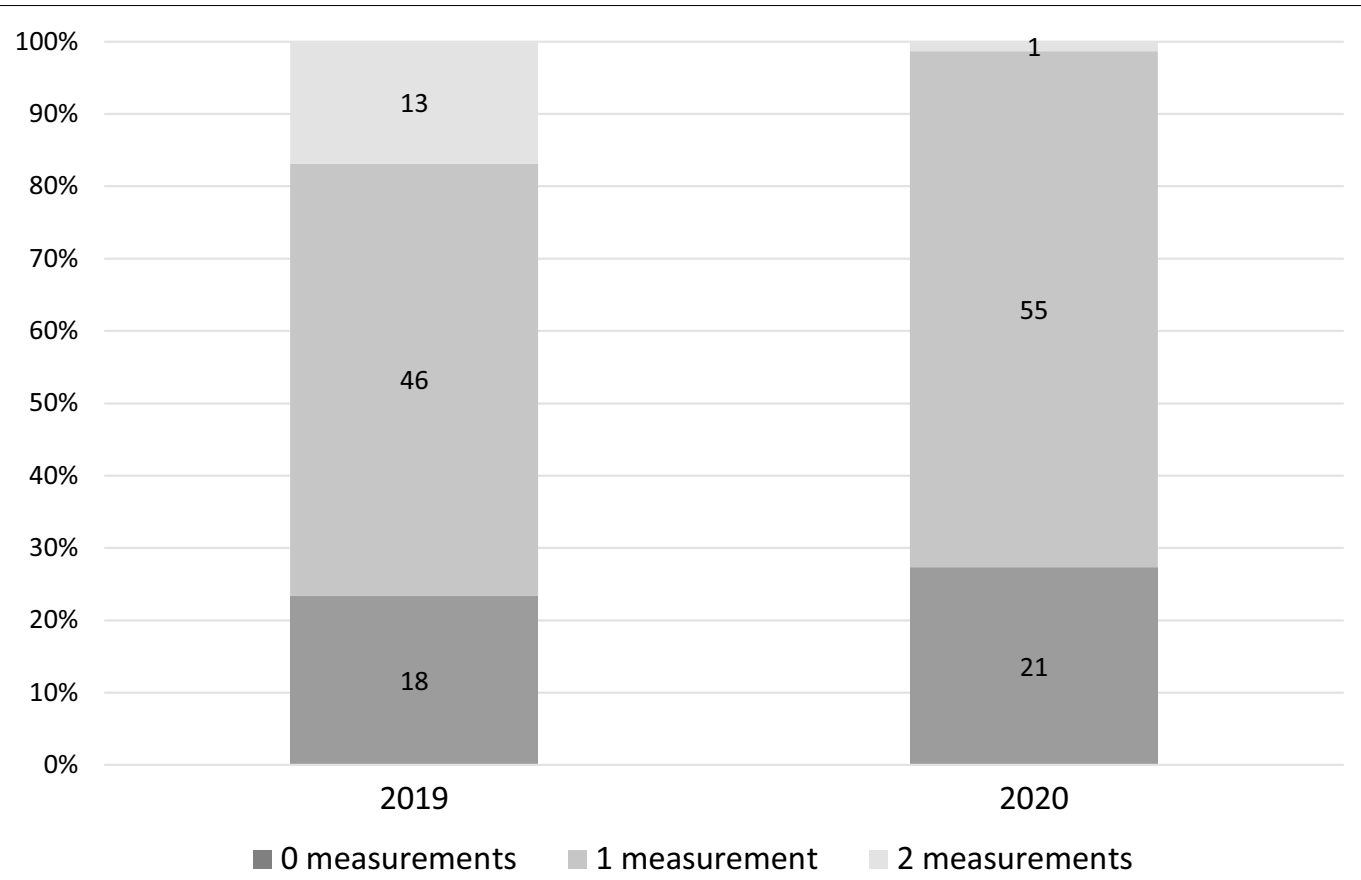

Fig. 2 Measurements from venous blood samples in 2019 and 2020

appointment and venous blood sampling did not differ significantly between the two measurement periods $(\mathrm{n}=21,27.3 \%$ in $2020, \mathrm{n}=18,23.4 \%$ in $2019 ; p=0.71)$.

Median Phe concentrations from DBS sent from home ( $\mathrm{n}=67$ patients; $424 \mu \mathrm{mol} / \mathrm{l}$ in both years) and median Phe concentrations from venous blood samples $(\mathrm{n}=48$ patients; $472 \mu \mathrm{mol} / \mathrm{l}$ in 2019 and $478 \mu \mathrm{mol} / \mathrm{l}$ in 2020;) did not differ significantly between 2019 and 2020 (Phe from DBS: $T=782.5, p=1.00$; Phe from venous blood samples: $T=602.5, p=0.88$ ).

Forty-five patients (58.4\%, 95\% CI 47.3-68.8\%) managed to keep their median Phe concentrations within the range recommended by their centre in 2019, 46 (59.7\%, 95\% CI 48.6-70.0\%) in 2020 (difference not significant, $p=0.23)$, and 38 (49.4\%, 95\% CI 38.5-60.3\%) patients in both years (Fig. 3).

Patients with a median Phe concentration within the recommended range in 2019 sent significantly less DBS in for Phe measurement (Mdn 2019=7; Mdn 2020=5; $T=577, p=0.01, r=0.36)$. Descriptively, they had higher Phe values from DBS in 2020 than in 2019, but this difference was not significant (Mdn $272 \mu \mathrm{mol} / 1$ in 2019 versus $375 \mu \mathrm{mol} / \mathrm{l}=$ in $2020, T=592, p=0.15$, $\mathrm{r}=0.27$ ).

In patients with a median Phe above the recommended range in 2019 the number of Phe measurements as well as the average Phe concentrations did not differ significantly between the two measurement periods

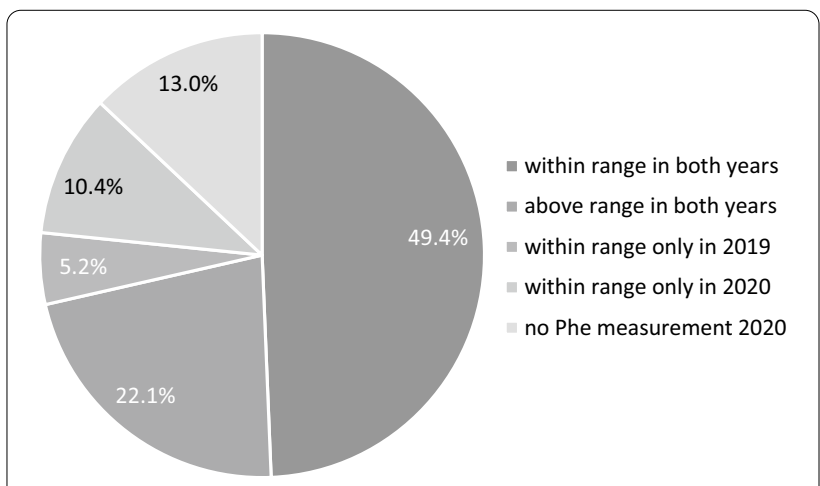

Fig. 3 Metabolic control in 2019 and 2020

(Phe-measurements: $T=264, p=0.49$; Phe concentrations: $T=156.5, p=1.00$ ).

Further subgroup analyses for male or female sex, and dietary only versus dietary plus sapropterin treatment revealed no association with changes in frequency of DBS-measurements and median Phe between 2019 and 2020.

\section{Discussion}

Our retrospective analysis focused on Phe concentrations, number of measurements of Phe from DBS, and number of clinical appointments including Phe assessment from venous blood samples in the year of the 
pandemic compared to the year before. During the pandemic, patients had fewer appointments and, consecutively, less venous blood samples taken. This is in line with the observation that individuals with a chronic illness experienced significantly more cancellations of scheduled medical procedures and appointments [8] and that both paediatric routine [17] and specific [18] care declined during the lockdown.

Even more prominent, though, was the effect on the low-threshold measurement of Phe from DBS. Sending DBS from home requires no further resources than a post office (which were open during lockdown) or a letterbox. Nevertheless, adherence to the recommended measurement intervals decreased significantly in the pandemic period. Especially adolescents over 16 years sent significantly less DBS in and the number of patients who had sent one or no sample at all for analysis tripled from 5.2 to $15.6 \%$. These findings suggest that during the lockdown a proportion of our patients, especially older teenagers, lost connection to the metabolic centre.

Adherence to treatment in PKU in terms of Phe concentrations in the target range generally declines with age [19]. The frequency of Phe measurement has not been a main target of such analyses. While most children up to 12 years have average Phe in the recommended range, only $49 \%$ of teenagers reach such good metabolic control $[20,21]$. Teens are easily lost to follow-up and may be lost forever in this vulnerable period, as the low numbers of young adults $(41 \%)$ and patients $>30$ years old $(31 \%)$ with Phe in the target range suggest $[20,21]$. Especially for teens but probably for the majority of paediatric PKU patients an active, communication-seeking follow-up e.g. by low-threshold reminders sent by digital messaging services or by e-mail [18] as well as structured telemedicine appointments [22-24] would most probably have been helpful to improve adherence and patient satisfaction [22-25].

Telemedicine as a substitute for outpatient clinic appointment had only been established in a single centre in Austria, which offered this service to only four PKU patients; its effects could not be quantified. Telemedicine has only slowly been introduced into the health system. In other settings e.g. in Turkey [22] or in Italy [24] it proved to be an effective tool during the pandemic. The authors reported more Phe concentrations in the target ranges [22, 24]. Main characteristic of the systems employed here were timely measurement of and comment on Phe values from DBS with recommendations on how to proceed further [22] and a complete and effective switch from in-person to remote consultations [24]. In Austria, a generally similar system with short Phe measurement turnaround times is the established way of care for PKU patients. Phe results from DBS sent to the centre as well as any actions to be taken are communicated to the patient/family by phone, usually by an experienced member of the metabolic team (e.g. a dietician). This system remained unaffected by the pandemic situation, which may explain that patients who continued to adhere to the recommended DBS measurement intervals had stable Phe concentrations during the pandemic. Since the incoming DBS starts the process of care, this system failed for patients who stopped sending them.

Male or female sex of the patient or type of treatment (diet, medication) did not influence the number of measurements or Phe concentrations during the pandemic. Interestingly, patients with good Phe control in 2019 sent significantly less DBS for analysis and tended to have higher Phe values in 2020 (yet, median values were still within the target range). We hypothesize that patients who had their disease management actions well embedded in their daily routine may have partially lost this control when everyday life changed so significantly during the pandemic. Beyond the mere change of everyday life, diminished adherence-especially of adolescents-may also be caused by the increased stress and emotional disturbances children and adolescents experienced during the pandemic with lockdowns and school closures. During the pandemic, adolescents reported not only more worries and fears but also feelings of overtiredness, underactivity, withdrawal and sadness [26] which make active disease management in terms of sending samples less probable.

\section{Conclusion}

During the COVID-pandemic, PKU patients had less appointments and venous blood sampling for complete amino acid assessment. Some PKU patients stopped sending DBS to their metabolic centre. Those who kept up their follow-up maintained stable Phe values. We conclude that our follow-up system, which is based on DBS sent in by patients/families to trigger communication with the metabolic team, was sufficient in itself and served adherent patients well. It failed, however, to actively retrieve patients who stopped or reduced DBS measurements. Telemedicine and active contacting of patients should complement systems of care for PKU and other metabolic patients not only during but also after the pandemic.

\section{Acknowledgements \\ Selina Krebs and Sophie StraßI helped with data retrieval.}

\section{Authors' contributions}

MHu provided the original concept of the study, coordinated the study, organised data collection, and wrote main parts of the manuscript. MBK, DK, BG, DM, BP, JS, JZ, SSB and SBW provided data of PKU patients. MHe prepared the data for analysis, conducted the statistical analysis and wrote the respective parts of the manuscript. All authors read and approved the final version of the manuscript. 


\section{Funding}

This study had no specific funding.

\section{Availability of data and materials}

Please contact author for data requests.

\section{Declarations}

\section{Ethics approval and consent to participate}

This study used retrospective anonymised data only. Ethics approval and consent to participate were not necessary to be obtained.

\section{Consent for publication}

Not applicable.

\section{Competing interests}

The authors of this manuscript declare no competing interests but disclose the following: MHu has received research grants from Nutricia Metabolics and consultancy honoraria from SOBI, Aeglea, Shire, Sanofi, and Orphan Europe. SSB has received research grants from Nutricia Metabolics and consultancy honoraria from Nutricia Metabolics and Dr. Schär. MHe, MBK, DK, BG, DM, BP, JS, JZ and SBW have nothing to disclose related to the contents of this study.

\section{Author details}

${ }^{1}$ Department of Pediatrics and Adolescent Medicine, Division of Pediatric Pulmonology, Allergology and Endocrinology, Medical University of Vienna, Vienna, Austria. ${ }^{2}$ Department of Pediatrics and Adolescent Medicine, Division of General Pediatrics, Medical University of Graz, Graz, Austria. ${ }^{3}$ Department of Pediatrics I, Inherited Metabolic Disorders, Medical University of Innsbruck, Innsbruck, Austria. ${ }^{4}$ University Children's Hospital Salzburg, Paracelsus Medical University, Salzburg, Austria. ${ }^{5}$ Amalia Children's Hospital, Radboudumc, Nijmegen, The Netherlands. ${ }^{6}$ Division of Metabolism and Children's Research Center, University Children's Hospital Zürich, Zürich, Switzerland. ${ }^{7}$ Department of Paediatrics, Landeskrankenhaus Bregenz, Carl-Pedenz-Str. 2, 6900 Bregenz, Austria.

Received: 2 July 2021 Accepted: 12 August 2021

Published online: 19 August 2021

\section{References}

1. Gersting SW, Kemter KF, StaudigI M, Messing DD, Danecka MK, Lagler FB, Sommerhoff CP, Roscher AA, Muntau AC. Loss of function in phenylketonuria is caused by impaired molecular motions and conformational instability. Am J Hum Genet. 2008;83(1):5-17.

2. http://www.biopku.org/home/pah.asp. Accessed 9 Dec 2020.

3. Longo N, Dimmock D, Levy H, et al. Evidence- and consensus-based recommendations for the use of pegvaliase in adults with phenylketonuria. Genet Med. 2019;21(8):1851-67. https://doi.org/10.1038/ s41436-018-0403-z.

4. https://de.wikipedia.org/wiki/COVID-19-Pandemie_in_\%C3\%96sterreich. Accessed 14 April 2021

5. Ashikkali L, Carroll W, Johnson C. The indirect impact of COVID-19 on child health. Paediatr Child Health (Oxford). 2020;30(12):430-7. https:// doi.org/10.1016/j.paed.2020.09.004.

6. Conlon C, McDonnell T, Barrett M, Cummins F, Deasy C, Hensey C, McAuliffe E, Nicholson E. The impact of the COVID-19 pandemic on child health and the provision of Care in Paediatric Emergency Departments: a qualitative study of frontline emergency care staff. BMC Health Serv Res. 2021;21(1):279. https://doi.org/10.1186/s12913-021-06284-9.PMID:33766 026:PMCID:PMC7993902.

7. Elmonem MA, Belanger-Quintana A, Bordugo A, Boruah R, Cortès-Saladelafont E, Endrakanti M, Giraldo P, Grünert SC, Gupta N, Kabra M, Knerr I, Krämer J, Kuster A, Levtchenko E, Ngu LH, Rovira-Remisa MM, Sass JO, Sykut-Cegielska J, Tummolo A, van den Heuvel LP. The impact of COVID19 pandemic on the diagnosis and management of inborn errors of metabolism: a global perspective. Mol Genet Metab. 2020;131(3):285-8. https://doi.org/10.1016/j.ymgme.2020.09.004.
8. Topriceanu CC, Wong A, Moon JC, Hughes AD, Bann D, Chaturvedi N, Patalay P, Conti G, Captur G. Evaluating access to health and care services during lockdown by the COVID-19 survey in five UK national longitudinal studies. BMJ Open. 2021;11(3): e045813. https://doi.org/10.1136/bmjop en-2020-045813.

9. D'Onofrio L, Pieralice S, Maddaloni E, Mignogna C, Sterpetti S, Coraggio L, Luordi C, Guarisco G, Leto G, Leonetti F, Manfrini S, Buzzetti R. Effects of the COVID-19 lockdown on glycaemic control in subjects with type 2 diabetes: the glycalock study. Diabetes Obes Metab. 2021. https://doi. org/10.1111/dom.14380.

10. Cohen J. Statistical power analysis for the behavioral sciences. In: Second Edition. Lawrence Erlbaum Associates, Publishers; 1988

11. https://www.graphpad.com/quickcalcs/. Accessed May 2021.

12. APS Empfehlungen. http://www.aps-med.de/site/store/recommenda tions/Therapy_of_patients_with_Phenylketonuria\%20_DE.pdf. Accessed 22 April 2020

13. Ballhausen $D$, Baumgartner $M$, Bonafé $L$, et al. Empfehlungen für die Behandlung der Phenylketonurie und Hyperphenylalaninämie. Paediatrica. 2006;17:2.

14. van Wegberg AMJ, MacDonald A, Ahring K, et al. The complete European guidelines on phenylketonuria: diagnosis and treatment. Orphanet J Rare Dis. 2017;12:162.

15. MacDonald A, van Wegberg AMJ, Ahring K, et al. PKU dietary handbook to accompany PKU guidelines [published correction appears in Orphanet J Rare Dis. 2020 Sep 1;15(1):230]. Orphanet J Rare Dis. 2020;15(1):171. https://doi.org/10.1186/s13023-020-01391-y.

16. Vockley J, Andersson HC, Antshel KM, et al. Phenylalanine hydroxylase deficiency: diagnosis and management guideline. Genet Med. 2014;16:188-200.

17. Somekh I, Somech R, Pettoello-Mantovani M, Somekh E. Changes in routine pediatric practice in light of coronavirus 2019 (COVID-19). J Pediatr. 2020;224:190-3. https://doi.org/10.1016/j.jpeds.2020.05.053.

18. Kendzerska T, Zhu DT, Gershon AS, Edwards JD, Peixoto C, Robillard R, Kendall CE. The effects of the health system response to the COVID-19 pandemic on chronic disease management: a narrative review. Risk Manag Healthc Policy. 2021;15(14):575-84. https://doi.org/10.2147/RMHP. S293471.

19. Beghini M, Resch FJ, Möslinger D, Konstantopoulou V, Karall D, SchollBürgi S, Brunner-Krainz M, Plecko B, Spenger J, Kautzky-Willer A, Scherer T, Hufgard-Leitner M. Project, "Backtoclinic I": an overview on the state of care of adult PKU patients in Austria. Mol Genet Metab. 2021. https://doi. org/10.1016/j.ymgme.2021.05.00.

20. Jurecki ER, Cederbaum S, Kopesky J, Perry K, Rohr F, Sanchez-Valle A, Viau KS, Sheinin MY, Cohen-Pfeffer JL. Adherence to clinic recommendations among patients with phenylketonuria in the United States. Mol Genet Metab. 2017;120(3):190-7. https://doi.org/10.1016/j.ymgme.2017.01.001 (Epub 2017 Jan 6 PMID: 28162992).

21. Peres M, Almeida MF, Pinto ÉJ, Carmona C, Rocha S, Guimas A, Ribeiro R, Martins E, Bandeira A, MacDonald A, Rocha JC. Implementing a transition program from paediatric to adult services in phenylketonuria: results after two years of follow-up with an adult team. Nutrients. 2021;13(3):799. https://doi.org/10.3390/nu13030799.PMID:33671057;PMCID:PMC80 01271.

22. Zubarioglu T, Hopurcuoglu D, Uygur E, Ahmadzada S, Oge-Enver E, Isat E, Cansever MS, Kiykim E, Aktuglu-Zeybek C. The impact of telemedicine for monitoring and treatment of phenylketonuria patients on metabolic outcome during coronavirus disease-19 outbreak. Telemed J e-Health. 2021. https://doi.org/10.1089/tmj.2020.0569.

23. Parise M, Tartaglione L, Cutruzzolà A, Maiorino MI, Esposito K, Pitocco D, Gnasso A, Irace C. Teleassistance for patients with type 1 diabetes during the COVID-19 pandemic: results of a pilot study. J Med Internet Res. 2021;23(4): e24552. https://doi.org/10.2196/24552 (PMID: 33769945)

24. Rovelli V, Zuvadelli J, Ercoli V, Montanari C, Paci S, Dionigi AR, Scopari A, Salvatici E, Cefalo G, Banderali G. PKU and COVID19: how the pandemic changed metabolic control. Mol Genet Metab Rep. 2021;27:100759. https://doi.org/10.1016/j.ymgmr.2021.100759.

25. Kanc K, Komel J, Kos M, Wagner J. H(ome)bA1c testing and telemedicine: high satisfaction of people with diabetes for diabetes management during COVID-19 lockdown. Diabetes Res Clin Pract. 2020;166:108285. https://doi.org/10.1016/j.diabres.2020.108285. 
26. Schmidt SJ, Barblan LP, Lory I, Landolt MA. Age-related effects of the COVID-19 pandemic on mental health of children and adolescents. Eur J Psychotraumatol. 2021;12(1):1901407. https://doi.org/10.1080/20008198. 2021.1901407.

\section{Publisher's Note}

Springer Nature remains neutral with regard to jurisdictional claims in published maps and institutional affiliations.
Ready to submit your research? Choose BMC and benefit from:

- fast, convenient online submission

- thorough peer review by experienced researchers in your field

- rapid publication on acceptance

- support for research data, including large and complex data types

- gold Open Access which fosters wider collaboration and increased citations

- maximum visibility for your research: over 100M website views per year

At BMC, research is always in progress.

Learn more biomedcentral.com/submissions 